\title{
Multicentric Hyaline-Vascular Castleman Disease: A Case Report
}

\author{
APARNA DAS, ${ }^{1}$ SANJ ANA TARANNUM, ${ }^{2}$ TAHERA KONA, ${ }^{2}$ SANTANU KUMAR SAHA, ${ }^{3}$ MA KAHHAR ${ }^{4}$
}

\begin{abstract}
:
Castleman disease is a rare lymphoproliferative disorder. Contrary to its closest differential of lymphoma, the disease tends to run a benign course. However the multicentric variety, which is usually of the plasma cell type, has a more sinister prognosis. It is commonly associated with HIV infection. We report a case of a 65 year old man presenting with recurrent episodes of swelling of the whole body and diarrhoea for 3 years. Physical examination revealed generalized lymphadenopathy with hepato-splenomegaly and ascites. Lymph node biopsy revealed histopathological changes consistent with hyaline-vascular type of Castleman disease (multicentric). He was HIV negative. Patient was treated with high dose corticosteroids and discharged with follow up advice.
\end{abstract}

Key wards: lymphadenopathy, lymphoma, Castleman disease

\section{Introduction:}

Castleman disease, also known as giant lymph node hyperplasia and angiofollicular lymph node hyperplasia, was first described in 1956 by Dr. Benjamin Castleman. ${ }^{1}$ It is a rare lymphoproliferative disorder of unknown aetiology but has specific risk factors, e.g. HIV and HHV-8. It has been classified clinically as unicentric (localized) and multicentric types and histologically as hyaline-vascular, plasma cell and mixed types. ${ }^{2}$ Unicentric hyaline-vascular types run a more benign course in comparison to multicentric plasma cell types which often result in fatalities from infectious complications, multi-organ failure and development of malignancies such as lymphoma (Hodgkin and non-Hodgkin) and Kaposi's sarcoma. ${ }^{3,4,5}$ Multicentric Castleman disease is usually of the plasma cell variant ${ }^{6}$ and associated with HIV as well as HHV8. Surgical treatment is curative for localized disease but the multicentric variety has been approached with a combination of steroids, chemotherapy, radiotherapy, immunotherapy (rituximab) and newer drugs. A satisfactory outcomefor any single or combined modalities of treatment in case of multicentric disease is yet to be achieved. We report a case of multicentric hyaline vascular type of Castleman disease in an HIV negative 65 year old man due to rarity of the condition.

\section{Case Report:}

In August of 2013, a 65-year-old retired textile mill worker presented to us with recurrent episodes of swelling of the

1. Assoc. Prof., Dept.of Medicine, Dhaka Medical College \& Hospital

2. HMO, Dept.of Medicine, Dhaka Medical College \& Hospital

3. IMO, Dept.of Medicine, Dhaka Medical College \& Hospital

4. Professor, Dept. of Medicine, Dhaka Medical College \& Hospital

Correspondence: Dr. Aparna Das, Assoc. Prof., Dept.of Medicine, Dhaka Medical College \& Hospital. e-mail: aparna_0191@yahoo.com body and recurrent bouts of diarrhea for last 3 years. Swelling first appeared in the legs and gradually involved the abdomen. There was no associated shortness of breath or scanty micturition. He also complained of frequent episodes of diarrhoea which mostly contained undigested food particles and mucus but no blood. Each diarrhoeal episode lasted for 2 to 5 days. Abdominal bloating, nausea, vomiting, loss of appetite and loss of about $50 \%$ of his previous body weight accompanied these symptoms. For the last 2 months, he developed low grade intermittent fever with evening rise of temperature but fever was not documented. He gave no history of any tuberculosis contact. There were no associated

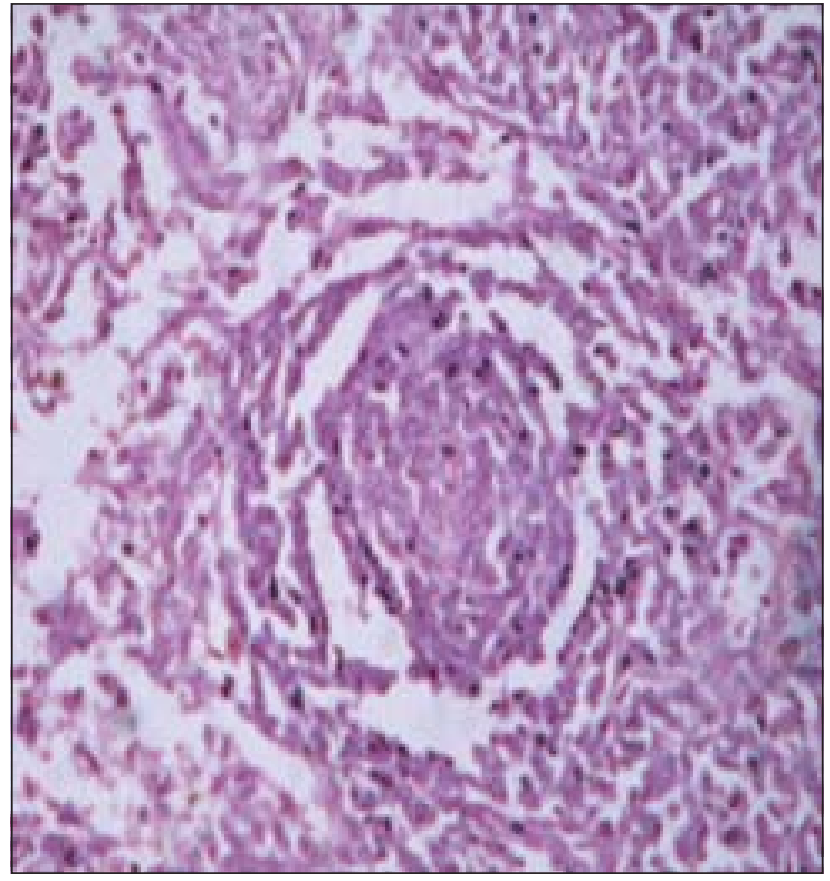

Fig.-1: Central hyalinization with concentric layers of lymphocytes suggestive of castleman disease. 
respiratory or abdominal symptoms, skin rashes, joint pains or tingling numbness of the extremities. He had no history of any blood transfusion or jaundice. He had not suffered from any major illness previously. He was an ex-smoker with a smoking history of 5 pack years; he had no history of alcohol intake.

Physical examination revealed an emaciated, mildly anaemic and oedematous man with generalized (cervical and axillary) lymphadenopathy. Abdominal examination revealed hepatosplenomegaly with clinical evidence of ascites. There was a systolic flow murmur in the pulmonary area and another systolic murmur in the aortic area without radiation to the carotids. Chest examination was unremarkable.

A full blood count showed a haemoglobin level of $10.4 \mathrm{~g} / \mathrm{dl}$ and a slightly raised ESR of $26 \mathrm{~mm}$ in the $1^{\text {st }}$ hour. Total and differential WBC count was normal. Peripheral blood film revealed a normochromic normocytic anaemia. CRP level was slightly raised. Urine routine microscopy was also normal (no proteinuria). A Mantoux test came positive $(17 \mathrm{~mm})$. Liver and renal function tests were all within the normal limits.

Ultrasonography of the whole abdomen revealed moderate ascites with hepato-splenomegaly. Ascitic fluid study revealed exudative ascites with $90 \%$ lymphocytes (total white cell count was $1200 / \mathrm{ml}$ ). Chest X ray was normal. Echocardiogram showed normal LV function with aortic sclerosis. An endoscopy of the upper GIT showed gastritis but colonoscopy was normal. A lymph node biopsy (from the axillary lymph nodes) revealed histopathological changes consistent with hyaline vascular type of Castleman disease.

To elucidate the risk factors and complications, a serological test for HIV antibody and protein electrophoresis were carried out. Both came out negative. A bone marrow aspiration study showed reactive changes. Due to limited facilities, we could not test for HHV-8 or immunocytochemistry.

As the patient couldn't afford rituximab and refused chemotherapy, he was started on high dose steroids (15 mg of dexamethasone for 7 days). He was self-discharged with follow up advice.

\section{Discussion:}

Castleman disease has been fancifully termed 'The Lymphoma Impostor' by Denenberg ${ }^{7}$ as it presents with feature indistinguishable clinically from those of lymphoma. Though the aetiology is yet to be discovered, the lymphoid proliferation results possibly from increased production of the cytokine Interleukin 6 (Il-6). ${ }^{8}$

Localized CD is usually asymptomatic in over $50 \%$ of patients ${ }^{9}$ whereas multicentric CD is always presents with symptoms due to elevated levels of Il-6 such as asthenia (65\%), weight loss(67\%) and fever(69\%). ${ }^{10}$ Generalized lymphadenopathy involving 4 sites on an average occurs $n$ $84 \%$ cases and hepatosplenomegaly is quite common. ${ }^{10}$

Our patient presented with all these features which complies with the literature. However the diarrhea and generalized body swelling were uncommon in the literature, only to be found in patients with intestinal amyloidosis. ${ }^{11}$ Due to lack of general well being of our patient, a rectal or intestinal biopsy could not be performed for exclusion of this complication. Plasma cell variant was more common among patients who developed systemic or intestinal amyloidosis. ${ }^{11}$

In case of multicentric disease, different regimens of chemotherapy have been found to be effective in the plasma cell variant but data regarding the hyaline vascular type is limited. Two similar cases of hyaline vascular type of multicentric disease in Bangladesh and abroad were managed with steroids resulting in symptomatic relief and disease remission. ${ }^{12,13}$

The systemic analysis of patients with Castleman disease by Talat revealed a 78\% three-year disease free survival rate for patients with HIV negative multicentric hyaline vascular (and unicentric plasma cell type) variants. ${ }^{14}$ The markedly different outcomes and disease associations of the CD variants leaves room for further studies, particularly regarding the modalities of treatment in our country where facilities are often limited.

\section{Conclusion:}

We report this case for its unusual presentation with diarrhea and anasarca. A high index of suspicion is required to differentiate Castleman disease from various infectious causes of lymphadenopathy and lymphoma. A wrong label may have catastrophic consequences whereas a precise diagnosis may result in complete remission.

\section{Conflict of interest: None.}

\section{References:}

1. Castleman B, Iverson M, Menendez V. Localized mediastinal lymph node hyperplasia resembling thymoma. Cancer1956; 9: 822.

2. Keller AR, Hochholzer L, Castleman B. Hyaline vascular and plasma cell types of giant lymph node hyperplasia of the mediastinum and other locations. Cancer1972; 29: 670.

3. Oksenhendler E, Duarte M, Soulier J, Cacoub P, Welker Y and Cadranel J: MulticentricCastleman's disease in HIV infection: a clinical and pathological study of 20 patients. AIDS 1996; 10(1): 61-7. 
4. Oksenhendler E, Boulanger E, Galicier L, Du MQ, Dupin N, Diss TC, Hamoudi R, Daniel MT, Agbalika F, Boshoff C, Clauvel JP, Isaacson PG and Meignin V: High incidence of Kaposi sarcoma-associated herpes virus-related non-Hodgkin lymphoma in patients with HIV infection and multicentric Castleman disease. Blood 2002; 99(7): 2331-6.

5. Case records of the Massachusetts General Hospital;Weekly clinic-pathological exercises. Case 39: A66-year-oldman with demyelinative neuropathy and a retroperitoneal mass. $\mathrm{N}$ Engl J Med1990; 323: 895-908.

6. Frizzera G, Petersn BA, Bayrd ED, Goldman A. A systemic lymphoproliferative disorder with morphologic features of Castleman's disease: Clinical findings and clinicopathologic correlations in 15 patients. J ClinOncol 3.1985: 1202.

7. Denenberg S, Levine PA. Castleman's disease- the lymphoma impostor.Laryngoscope 1984; 94: 601-4.

8. BrouetJC, Levy Y. IL6 and lymphoproliferative disorders. Nouv Rev FrHematol.1991; 33: 433-6.
9. Herrada J, Cabanillas F, Rice L, Manning J, Pugh W: The clinical behaviour of localized and multicentric Castleman disease. Ann Intern Med.1998; 128(8): 657-62.

10. Sarrot-Reynauld F: Castleman's Disease; Orphanetencyclopaedia, August 2001. [http://www.orpha.net/data/ patho/GB/ukcastleman.

11. Miura A, Sato I, Suzuki C. Fatal diarrhea in a patient with Castleman's disease associated with intestinal amyloidosis. Internal Medicine1995; 34: 1106-1109.

12. Menezes BF, Morgan R, Azad M. Multicentric Castleman’s disease: a case report. Journal of Medical Case Reports 2007; 1: 78 .

13. Patwary MI, Hossain MA, Rahman MM, Chowdhury MAI, Rahman MK, Kabir MR. Castleman's Disease- A Case Report. BSMMU J. 2012; 5(1): 79-80.

14. Talat N, Schulte KM. Castleman's disease: systematic analysis of 416 patients from the literature. Oncologist. 2011; 16(9): 1316-24. 